\title{
The Important Role of Dendritic Cell (DC) in iNKT-Mediated Modulation of NK Cell Function in Chlamydia pneumoniae Lung Infection
}

\author{
Lei Zhao, ${ }^{1,2}$ Xiaoling Gao $\mathbb{D}^{1},{ }^{1}$ Hong Bai $\mathbb{D}^{1},{ }^{1}$ Antony George Joyee, ${ }^{1}$ Shuhe Wang, ${ }^{1}$ Jie Yang, \\ Weiming Zhao, ${ }^{3}$ and Xi Yang $\mathbb{C}^{1,3}$ \\ ${ }^{1}$ Department of Immunology, Faculty of Medicine, University of Manitoba, Winnipeg, Canada \\ ${ }^{2}$ Institute of Basic Medical Sciences, Qilu Hospital, Shandong University, Jinan, Shandong, China \\ ${ }^{3}$ Department of Pathogenic Biology, Shandong University School of Medicine, Jinan, Shandong, China \\ Correspondence should be addressed to Xi Yang; x.yang@umanitoba.ca
}

Received 13 December 2018; Revised 29 March 2019; Accepted 15 April 2019; Published 20 May 2019

Guest Editor: Luisa Cervantes-Barragan

Copyright ( 2019 Lei Zhao et al. This is an open access article distributed under the Creative Commons Attribution License, which permits unrestricted use, distribution, and reproduction in any medium, provided the original work is properly cited.

\begin{abstract}
Chlamydia pneumoniae (Cpn) infection causes multiple acute and chronic human diseases. The role of DCs in host defense against Cpn infection has been well documented. The same is true for invariant natural killer T (iNKT) cells and NK cells, but the interaction among cells is largely unknown. In this study, we investigated the influence and mechanism of iNKT cell on the differentiation and function of NK cell in Cpn lung infection and the role played by DCs in this process. We found that expansion of IFN- $\gamma$-producing NK cells quickly happened after the infection, but this response was altered in iNKT knockout (KO) mice. The expression of activation markers and the production of IFN- $\gamma$ by different NK subsets were significantly lower in KO mice than wild-type (WT) mice. Using in vitro DC-NK coculture and in vivo adoptive transfer approaches, we further examined the role of DCs in iNKT-mediated modulation of NK cell function. We found that NK cells expressed lower levels of activation markers and produced less IFN- $\gamma$ when they were cocultured with DCs from KO mice than WT mice. More importantly, we found that the adoptive transfer of DCs from the KO mice induced less NK cell activation and IFN- $\gamma$ production. The results provided evidence on the modulating effect of iNKT cell on NK cell function, particularly the critical role of DCs in this modulation process. The finding suggests the complexity of cellular interactions in Cpn lung infection, which should be considered in designing preventive and therapeutic approaches for diseases and infections.
\end{abstract}

\section{Introduction}

The role of DCs in host defense against infections has been well defined. In particular, we and others have found significant interaction of iNKT/NK cells with DCs which are important for $\mathrm{T}$ cell response in different infection settings [1-4]. In the present study, we intended to study the modulating effect of iNKT cell on NK cell and the involvement of DCs in this process.

NK cells are an important component of the innate immune system, contributing to host resistance to microbial infection such as viruses, bacteria, and certain parasites [5-7]. Some studies have demonstrated that human and murine NK cells are highly heterogeneous populations with multifunctional features $[8,9]$. In this context, murine NK cells can be grouped into four subsets based on CD11b and $\mathrm{CD} 27$ expression. The $\mathrm{CD} 11 \mathrm{~b}^{\text {low }} \mathrm{CD} 27^{\text {low }}, \mathrm{CD} 11 \mathrm{~b}^{\text {low }} \mathrm{CD} 27-$ high, $\mathrm{CD} 11 \mathrm{~b}^{\text {high }} \mathrm{CD} 27^{\text {high }}$, and $\mathrm{CD} 11 \mathrm{~b}^{\text {high }} \mathrm{CD} 27^{\text {low }} \mathrm{NK}$ subsets represent a continuous NK cell differentiation process [10]. Among these subsets, the $\mathrm{CD} 11 b^{\text {low }} \mathrm{CD} 27^{\text {high }}$ and $\mathrm{CD} 11 \mathrm{~b}^{\text {high }} \mathrm{CD} 27^{\text {high }}$ subsets exhibit enhanced cytokine production and higher responsiveness, while $\mathrm{CD} 11 \mathrm{~b}^{\text {high }} \mathrm{CD} 27^{\text {low }}$ NK subsets appear to be more tightly controlled due to their higher expression of inhibitory receptors [11]. The functional distinctions of NK subsets in immune responses have been discerned in several disease models $[12,13]$.

iNKT is an innate-like $\mathrm{T}$ lymphocyte sublineage that expresses NK cell markers and limited/semi-invariant $\mathrm{T}$ cell 
repertoire that recognize lipid in the context of nonclassical MHC-I molecule CD1d [14, 15]. Functional studies on iNKT cells have suggested a significant impact of these cells on immune regulation. After activation, iNKT cells produce a broad range of cytokines and provide surface stimulatory molecules to activate NK cells, T cells, B cells, and DCs [1, $16,17]$. Some studies have shown the modulating effect of iNKT cell on NK cell in infection and noninfection settings. Injection of soluble model antigen $\alpha$-galactosylceramide $(\alpha$ Galcer) which is a specific agonist for iNKT cells led to NK cell activation and proliferation and production of IFN- $\gamma$ in mice $[18,19]$. In addition, $\alpha$-Galcer-stimulated human iNKT cells also activated NK cells through an IL-2-dependent mechanism [20]. Furthermore, activated iNKT cells induced NK cell differentiation and affected NK cell education [21]. Interestingly, in infection settings, the effect of iNKT on NK cell functions appears variable in the literature [22-24]. One study showed that NK cells maintained its activity and protective function in the absence of iNKT cells during Trypanosoma cruzi infection [22]. Another study showed that iNKT cells suppressed IFN- $\gamma$ production by NK cells following acute influenza A virus infection [23]. In contrast, we reported previously that iNKT cells promote IFN- $\gamma$ production by $\mathrm{NK}$ cells during $C$. muridarum, a mouse strain of Chlamydia, infection [24]. The mixed findings suggest that the effect of iNKT cell on NK cell is likely infection specific; thus, it is important to specifically study particular pathogens.

Members of the Chlamydia family are obligate intracellular Gram-negative bacterial pathogens, which include several species and various serotypes. Previous studies have shown that the distinct cellular immune responses including NK/iNKT cells were induced by different species of Chlamydia particularly Cpn and C. muridarum (Cm) [25]. NK cells play a protective role in $C m$ infection [26-28], but one report showed that NK cells did not contribute to innate resistance to $C p n$ infection in a setting of $\mathrm{T}$ cell and $\mathrm{B}$ cell deficiencies $[29,30]$. Notably, the kinetics and functional involvement of NK cell response in Cpn infection have not been well clarified. Therefore, it is important to specifically test NK cell response and the effect of iNKT cells in Cpn infection. In addition, we have reported that iNKT cells can modulate the phenotype, cytokine production, and function of DCs in Cpn infection $[1,31]$. In particular, we found that iNKT cells could enhance DC IL-12p70 production in a CD40L-, IFN- $\gamma$-, and cell-cell contactdependent manner in the coculture system. Considering the important role of DCs in modulation of NK and iNKT cell function, it is natural to study the involvement of DCs in this process.

In the present study, through depletion of NK cell in vivo and direct comparison of WT and iNKT KO mice, we examined the involvement of $\mathrm{NK}$ cell response in host defense against Cpn infection and the effect of iNKT cells on NK cell differentiation and activation during the infection. Further, we explored the mechanism by which iNKT cells modulate NK cell activation and function, particularly the involvement of DCs in this process, using in vitro DC-NK coculture and in vivo adoptive transfer approaches.

\section{Materials and Methods}

2.1. Mice. Female C57BL/6 mice were bred and kept under a specific pathogen-free animal facility at the University of Manitoba. Breeding pairs of J $\alpha 18$ gene knockout (J $\alpha 18-/-)$ mice which lacked invariant iNKT cells in B6 background were kindly provided by Dr. Masaru Taniguchi (RIKEN Research Center for Allergy and Immunology) and maintained at the animal care facility of the University of Manitoba. All mice used were between 6 and 12 weeks old. All experiments were conducted in accord with the guidelines of the Canadian Council on Animal Care, and the protocol was approved by the ethical committee of the University of Manitoba.

2.2. Chlamydia. Cpn were propagated, purified, and quantified as previously described [1]. Briefly, Cpn was grown in HEp-2 cells in Eagle's MEM containing 10\% FBS. After 48 h culture, infected cells were harvested. Elementary bodies (EBs) were purified by discontinuous density gradient centrifugation. The purified EBs were measured by immunostaining and stored at $-80^{\circ} \mathrm{C}$. For mice infection, $5 \times 10^{6}$ inclusion-forming units (IFUs) of Cpn in $40 \mu \mathrm{l}$ final volume of PBS was used to inoculate mice intranasally. The same seed stock of EBs was used throughout the study.

2.3. Antibodies. Fluorescent-labeled mAbs and corresponding isotype controls were purchased from eBioscience or BioLegend. For analysis of NK subsets by flow cytometry, anti-CD3e-PE-Cy7, anti-NK1.1-PE, anti-NK1.1-APC, antiCD69-PE, anti-CD25-FITC, anti-CD11b-APC, anti-NK1. 1-Pacific Blue, anti-CD27-FITC, and anti-CD11b-APCCy7 were used.

2.4. Surface Marker and Intracellular Cytokine Staining. For in vivo experiments, the fresh splenocytes were stained by anti-CD3e-PE-Cy7, anti-NK1.1-APC, anti-CD69-PE, and anti-CD25-FITC for CD69 and CD25 expression. NK subset staining and analysis were performed as described previously [24]. For intracellular cytokine staining, cells were stimulated with PMA (50 ng/ml) and Ionomycin $(1 \mu \mathrm{g} / \mathrm{ml})$ and incubated in complete RPMI 1640 medium at $37^{\circ} \mathrm{C}$. After 3-hour incubation, brefeldin A was added, and cells were cultured for another 3 hours to accumulate cytokines intracellularly. Cells were subsequently washed and blocked for 10 min with anti-CD16/CD32 in FACS buffer (Dulbecco's PBS, 2\% heat-inactivated FBS, $0.09 \%$ sodium azide) and then surface stained with the appropriate Abs. Cells were fixed, permeabilized, and subsequently stained with APC-anti-IFN- $\gamma$ for $30 \mathrm{~min}$. Stained cells were washed and analyzed using an LSR II flow cytometer. The data were subsequently analyzed with FACS express software.

2.5. Isolate DCs and Adoptive Transfer. DCs were isolated from splenocytes according to the manufacturer's instructions as described previously [1]. Briefly, spleens from either $\mathrm{J} \alpha 18$-/- mice or $\mathrm{C} 57 \mathrm{BL} / 6$ mice were aseptically collected at a certain time after infection and digested into single cells using $2 \mathrm{mg} / \mathrm{ml}$ collagenase D. DCs were purified using magnetic CD11c microbeads and MACS-positive 
selection column (Miltenyi Biotec, Auburn, CA). The purity of the isolated CD11c+ cells was up to $90 \%$ based on flow cytometric analysis.

For adoptive transfer, DCs were isolated from either Cpninfected J $\alpha 18$-/- mice or C57BL/6 mice, and $2 \times 10^{6}$ DCs in sterile PBS were adoptively transferred intravenously (i.v.) to naive C57BL/6 recipients. Twenty-four hours after adoptive transfer, the mice were intranasally inoculated with $5 \times 10^{6}$ IFUs of Cpn. The recipient mice were sacrificed at day 3 p.i., and the expression of activation markers and IFN- $\gamma$ production by NK cells were measured by flow cytometry.

2.6. NK Cell Purification. Spleen cells from uninfected mice were prepared, and NK cells were isolated by negative selection using an NK cell isolation kit (Miltenyi Biotec) according to the manufacturer's instructions. NK cells (NK1.1 $+\mathrm{CD} 3 \mathrm{e}-$ ) were $>90 \%$ pure following separation as determined by flow cytometry.

2.7. DC and NK Cell Coculture. Purified DCs $\left(1 \times 10^{6}\right)$ from either Cpn-infected J $\alpha 18$-/- mice or C57BL/6 mice were cocultured with NK cells $\left(2 \times 10^{5}\right)$ isolated from uninfected $\mathrm{C} 57 \mathrm{BL} / 6$ mice in a $96-$ well round bottom plate at $37^{\circ} \mathrm{C}$. After $48 \mathrm{~h}$, cells were collected for intracellular cytokine staining to analyze IFN- $\gamma$ production by NK cells following the protocol described above. Meanwhile, concentrations of IFN- $\gamma$ in the supernatants were measured by ELISA.

2.8. NK Depletion In Vivo. Mice were injected i.p. with $30 \mu \mathrm{l}$ anti-asialo-GM1 (Wako) in $300 \mathrm{ml}$ PBS to deplete NK cells in vivo. Control mice received appropriate normal rabbit IgG (Wako). Injections were performed 3 days prior to Chlamydia infection and repeated every 3 days to maintain depletion. The depletion of NK cells (95\%) by this treatment was confirmed by flow cytometric analysis.

2.9. Statistical Analysis. Statistical analysis of the data was performed as indicated using either unpaired Student's $t$-test or one-way ANOVA (GraphPad Prism software; version 5). Values of $p<0.05$ were considered significant.

\section{Results}

3.1. CD27 $7^{\text {high }} \mathrm{NK}$ Cells Expand after Respiratory Infection with Cpn. To test whether NK cells respond to Cpn infection, the percentage and the absolute number of NK cells were analyzed by flow cytometry at various time points after respiratory tract Cpn exposure. NK cells were identified as NK1.1 $+\mathrm{CD} 3 \mathrm{e}$ - cells. As shown in (Figures 1(a) and 1(b), there was a modest increase of the percentage of NK1.1-expressing cells in the spleen at day 1 after Cpn infection which peaked at day 3. At day 5, the percentage of NK cells started to decrease. A similar kinetic change of NK cells was also observed in the lung (Figure S1A and B). The absolute number of NK cells in the spleen also increased at day 1 and reached the peak at day 3 (Figure 1(c)). The total number of NK cells expanded about 2.5-folds in the spleen (Figure 1(c))) and 4-folds in the lung (Figure S1C) at their peak level at day 3.

It has been reported that murine NK cells can be grouped into 4 subsets based on surface CD11b and CD27 expression
$[10,11]$. To explore whether the NK subsets were affected by Cpn infection, the pattern of NK subsets was examined. As shown in Figures 1(d) and 1(e), Cpn infection resulted in a significant increase of the proportion of CD2 $7^{\text {high }} \mathrm{NK}$ cells compared with uninfected mice. The frequency of both $\mathrm{CD} 11 \mathrm{~b}^{\text {low }} \mathrm{CD} 27^{\text {high }}$ and $\mathrm{CD} 11 \mathrm{~b}^{\text {high }} \mathrm{CD} 27^{\text {high }} \mathrm{NK}$ cells was nearly doubled at day 7 p.i. The increase of CD2 $7^{\text {high }} \mathrm{NK}$ cells was accompanied by a reduction of $\mathrm{CD} 11 \mathrm{~b}^{\text {high }} \mathrm{CD} 27^{\text {low }}$ NK subset. Together, the results indicate that Cpn infection induces rapid expansion of $\mathrm{NK}$ cells, especially the $\mathrm{CD} 27^{\text {high }}$ subsets.

3.2. NK Cells Are Activated and Produce IFN- $\gamma$ after Cpn Infection. To determine whether NK cells are an activated phenotype in response to Cpn infection, we measured the expression of two early activation markers, CD69 and CD25, on NK cells in a kinetic manner. We found that Cpn infection rapidly increased CD69 expression on NK cells as early as day 1 , peaking at day 3 , with $45 \%$ NK cells in the spleen (Figures 2(a) and 2(b)) expressing this marker. The level of CD25 on splenic NK cells (Figures 2(c) and 2(d)) was also significantly elevated at day 1 and peaked at day 3 p.i. Both CD69 and CD25 gradually decreased from the peak but remained high at day 9 when the experiment was terminated. Further, intracellular cytokine staining was performed to determine IFN- $\gamma$ production by NK cells following Cpn infection. We found that the percentage of IFN- $\gamma$-producing NK cells started to increase as early as day 1 p.i., with about $25 \%$ of NK cells stained positive for IFN- $\gamma$ at day 5 p.i. (Figure $2(\mathrm{e})$ ). About $5 \%$ of NK cells produced IFN- $\gamma$ in uninfected control mice. The high IFN- $\gamma$ production by NK cells remained during the period of the study. The results show that NK cells are activated and produce IFN- $\gamma$ in response to Cpn infection.

3.3. NK Cell Depletion Results in Increased Susceptibility to Cpn Lung Infection. To further confirm the role of NK cells in host defense against Cpn lung infection in immune intact mice, we used anti-asialo-GM1 treatment to deplete NK cells in vivo and examine its effect on host susceptibility to Cpn infection. We found that NK-depleted mice showed greater body weight loss (Figure 3(a)) and significantly higher bacterial burden in the lung compared with control antibody-treated mice (Figure 3(b)). The depletion of NK cells in the spleen and lung was confirmed by flow cytometry (Figure S2). The result suggested that NK cells played an important protective role in host defense against Cpn lung infection.

3.4. iNKT Deficiency Leads to Changes of NK Cell Subset Expansion. To address the impact of iNKT cell on the expansion of NK cells during Cpn infection, we first measured the number of NK cells in WT and iNKT KO (J $\alpha 18-/-)$ mice. We found that there is no significant difference in NK cell number between these two mouse strains before and after Cpn infection (Figure S3). Then, we analyzed the distribution of NK subsets based on their CD27 and CD11b expression in WT and iNKT KO mice before and after Cpn infection. At the steady state before 


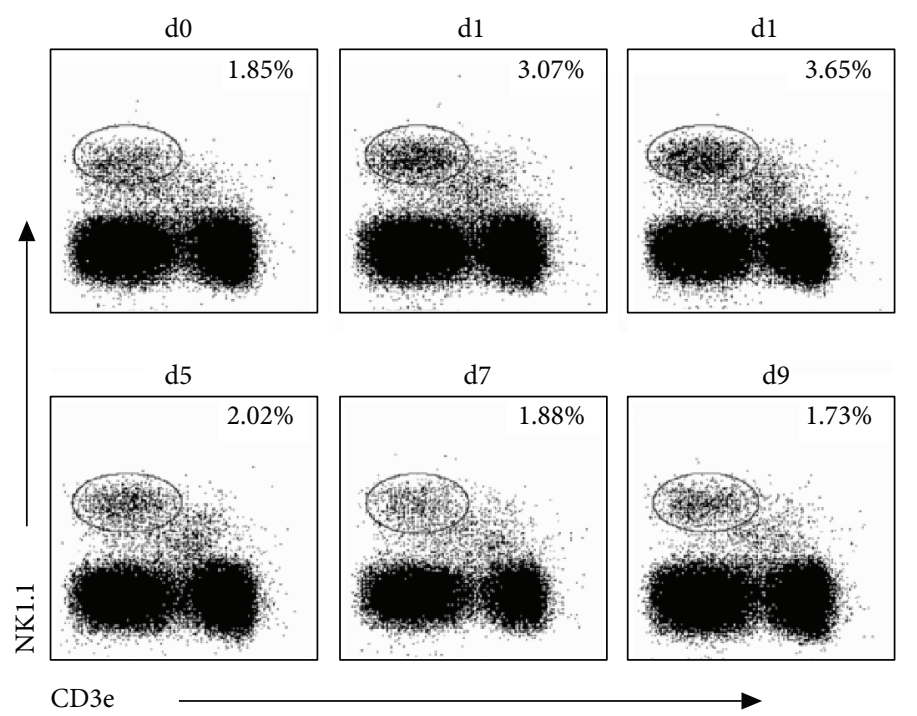

(a)

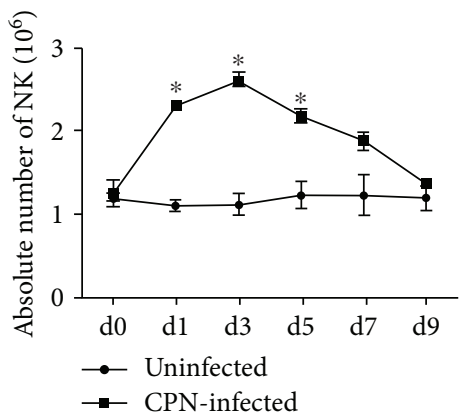

(b)

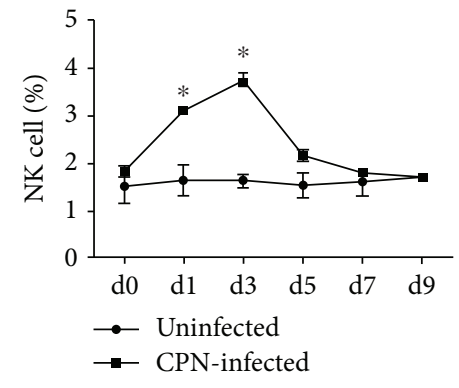

(c)

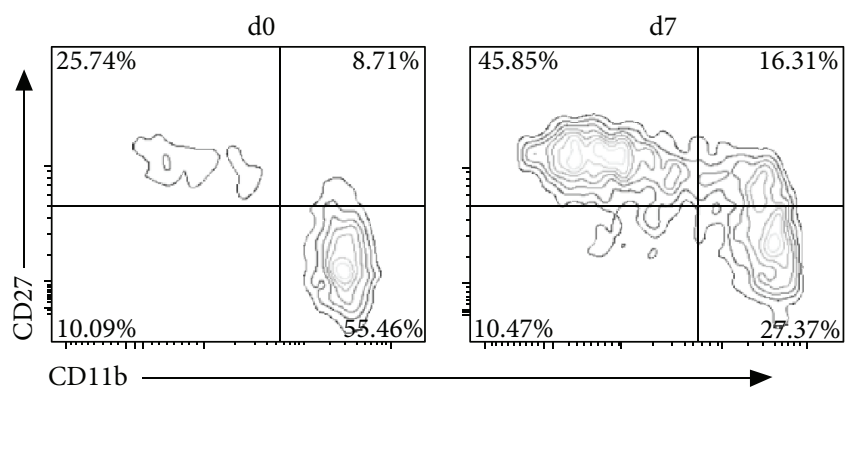

(d)

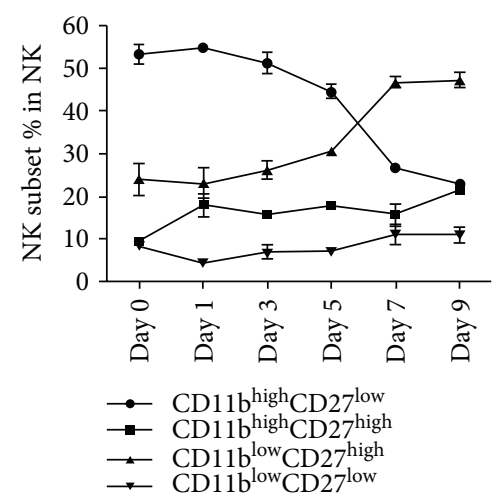

(e)

FIGURE 1: Cpn lung infection induces expansion of NK cell number and changes the distribution of NK subsets. Mice were infected with $5 \times 10^{6}$ IFUCpn intranasally and killed at specified time points. Splenocytes were stained for NK1.1 and CD3e. (a) Percentage of NK cells (NK1.1+CD3e-) among living lymphocytes was gated according to forward and side scatter. Representative dot plots are shown. (b) Kinetics of the percentage of NK cells. (c) Kinetics of the absolute number of NK cells per mouse spleen. (d) Based on CD11b and CD27 staining, NK cell subsets were analyzed after gating on NK1.1+CD3e- cells. Representative zebra plots for CD11b- and CD27-expressing NK cells before and after Cpn infection were shown. (e) Kinetics of the mean percentage of indicated NK cell subsets are plotted. Data are expressed as mean $(n=4) \pm \mathrm{SD}$ and represent three independent experiments. ${ }^{*} p<0.05$.

infection, the distribution of NK subsets was similar in iNKT $\mathrm{KO}$ and WT control mice. Following Cpn infection, the pattern of NK subsets was significantly altered in WT mice at day 7 p.i., showing a remarkable increase of the
$\mathrm{CD} 11 \mathrm{~b}^{\text {low }} \mathrm{CD} 27^{\text {high }}$ and $\mathrm{CD} 11 \mathrm{~b}^{\text {high }} \mathrm{CD} 27^{\text {high }} \mathrm{NK}$ subsets (Figure 4). Notably, the increase of the CD $27^{\text {high }}$ NK cells in iNKT KO mice was found at day 5 p.i., earlier than that shown in WT mice. Consequently, the frequency of 


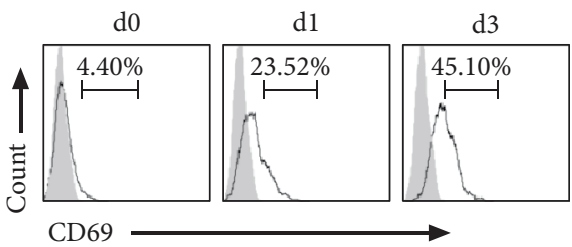

(a)

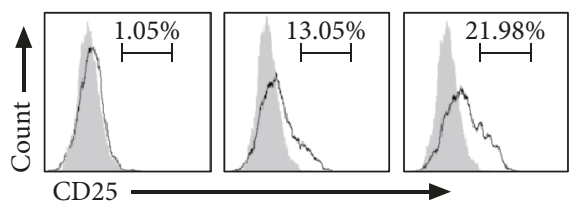

(c)

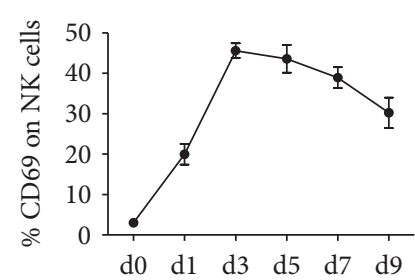

(b)

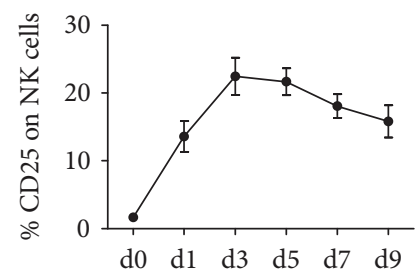

(d)

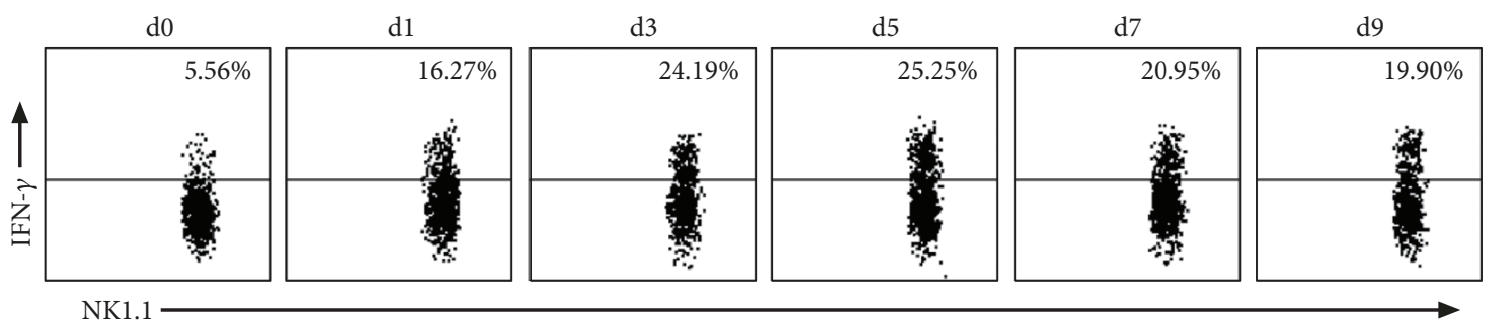

(e)

Figure 2: NK cells become activated and produce IFN- $\gamma$ in response to $C p n$ infection. After intranasal infection by $C p n$, mice were killed at different days, and splenocytes were stained for NK1.1, CD3e, CD25, and CD69. (a) Representative histogram of activation marker CD69 expression on NK cells at days 0, 1, and 3 p.i.: isotype control Ab staining (gray histograms) and infected mice (solid lines). (b) Kinetics of the expression of CD69 by NK cells. (c) Representative graph of the expression of activation marker CD25 on NK cells after infection: isotype control $\mathrm{Ab}$ staining (gray histograms) and infected mice (solid lines). (d) Kinetics of the expression of CD25 by NK cells. (e) Representative staining for intracellular IFN- $\gamma$ before and after Cpn infection. IFN- $\gamma$ production by splenic NK cells was assayed by intracellular cytokine staining on gated NK1.1+CD3e- population. The data represent one of at least three independent experiments and are shown as mean \pm SD for four mice at end time points.

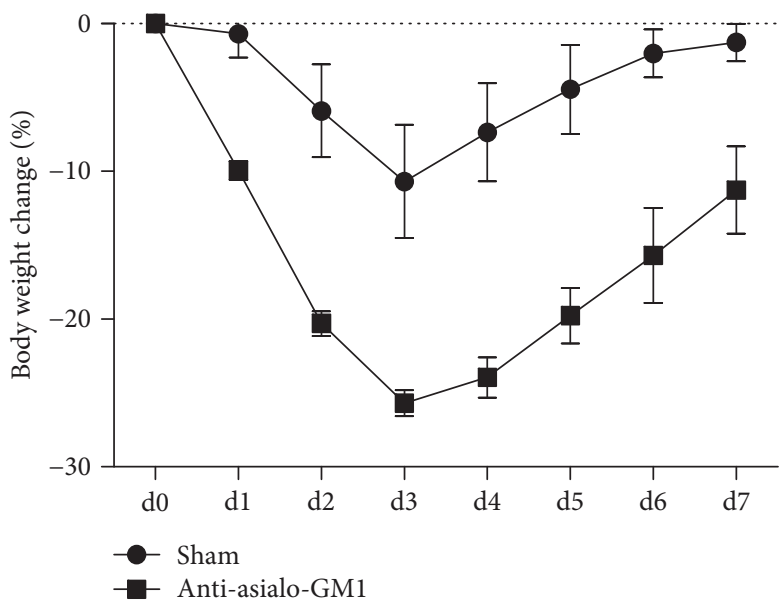

(a)

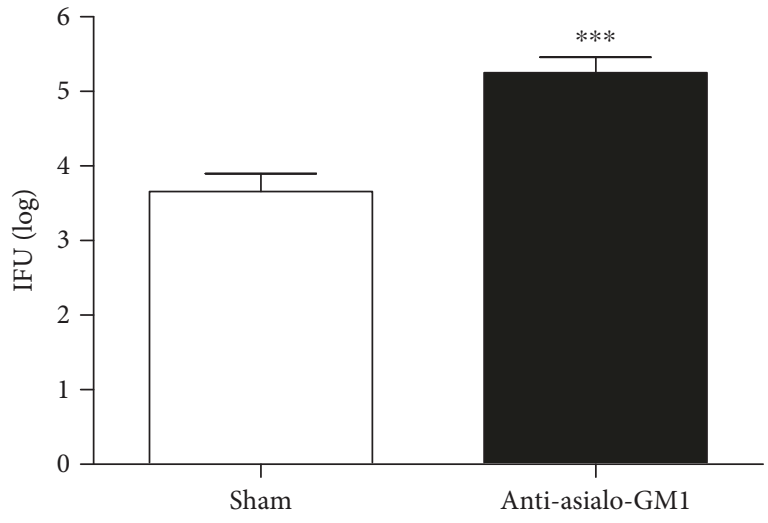

(b)

Figure 3: More severe disease in NK-depleted mice after Cpn lung infection. C57BL/6 mice were treated with anti-asialo-GM1 or control rabbit IgG during Cpn lung infection as described in Materials and Methods. (a) The body weight changes of the mice were monitored daily. Each time point represented the mean \pm SD of three mice. (b) Mice were sacrificed, and the lungs were collected for testing Cpn loads at day 7 p.i. The mean of $\log 10$-transformed IFUs per lung is presented. ${ }^{* * *} p<0.001$. 


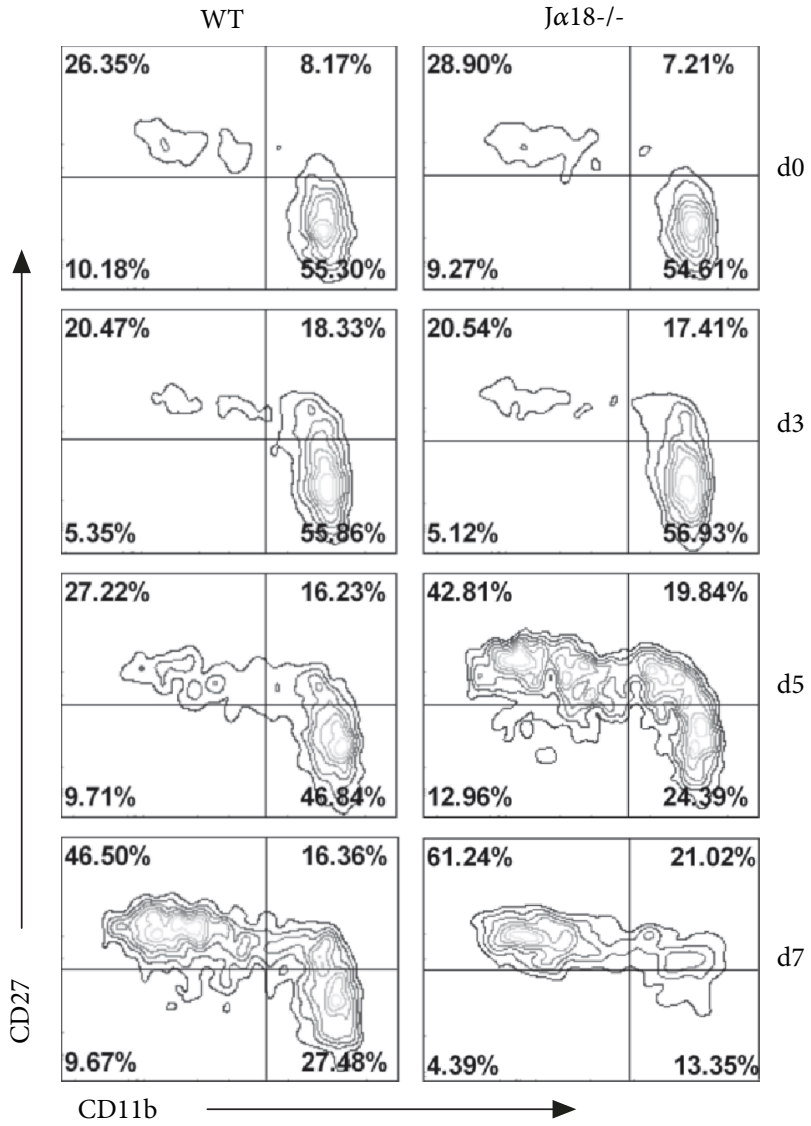

(a)

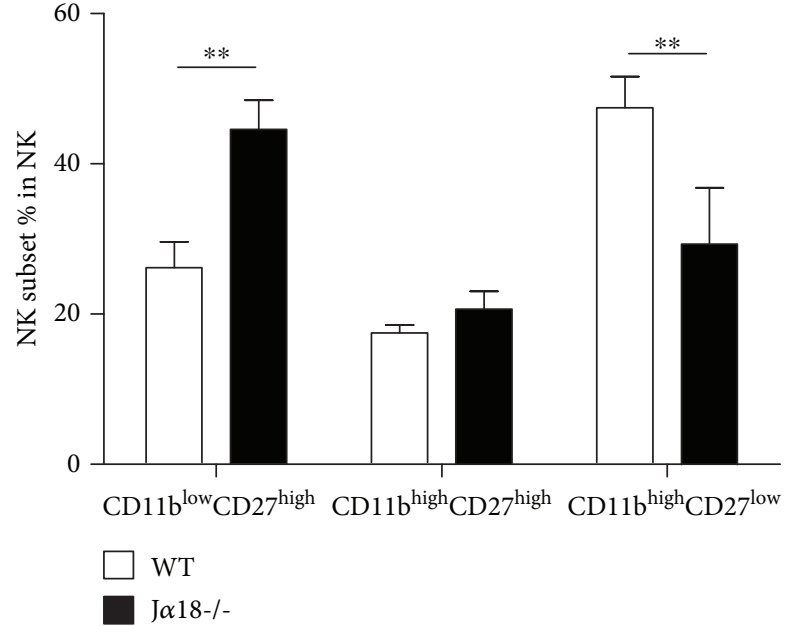

(b)

FIGURE 4: NK cells from J $\alpha 18$-/- mice show altered distribution of NK subsets during Cpn infection. Mice were killed at different days following intranasal infection with Cpn EBs $\left(5 \times 10^{6} \mathrm{IFUs}\right)$, and the splenocytes were prepared for flow cytometry. (a) Relative distribution of CD11b- and CD27-expressing NK cells at a steady state and at specified days after infection in WT mice and J $\alpha 18-/-$ mice. Zebra plots were shown from at least three independent experiments. (b) The bar summarizes the relative distribution of splenic NK subsets at day 5 p.i., which are shown as mean \pm SD for four mice. ${ }^{* *} p<0.01$.

$\mathrm{CD} 11 \mathrm{~b}^{\text {high }} \mathrm{CD} 27^{\text {low }} \mathrm{NK}$ subset showed an earlier decrease in iNKT KO mice than WT control. Therefore, iNKT deficiency appeared to promote the increase of $\mathrm{CD} 27^{\text {high }} \mathrm{NK}$ subset in the kinetics.

3.5. iNKT Deficiency Results in Compromised NK Activation and Reduced IFN- $\gamma$ Production by NK Cells following Cpn Infection. It has been reported that the murine $\mathrm{CD} 27^{\text {high }}$ NK cells exhibit potent responsiveness and enhanced cytokine production, whereas the $\mathrm{CD} 11 \mathrm{~b}^{\text {high }} \mathrm{CD} 27^{\text {low }}$ subset has a higher activation threshold [11]. Therefore, the increased frequency of the CD27 $7^{\text {high }} \mathrm{NK}$ cells in J $\alpha 18-/$ - mice might suggest an enhanced NK function in these mice. To test this possibility, we compared the activation status and cytokine production of NK cell in the CPn-infected WT and iNKT KO mice. Surprisingly, we found that the NK cells from iNKT KO mice showed much lower expression of CD69 (Figures 5(a) and 5(b)) and CD25 (Figures 5(c) and 5(d)) than WT mice at day 1 and day 3 p.i. Further analysis revealed that the levels of CD69 (Figure 5(e)) and CD25 (Figure 5(f)) expression in all the NK subsets from iNKT
KO mice were lower than that of WT mice. The data did not support the notion of higher NK activation in iNKT KO mice than WT mice although the percentage of $\mathrm{CD} 27^{\text {high }}$ NK cells is higher in iNKT KO mice.

We further investigated the influence of iNKT cells on IFN- $\gamma$ production by NK cells through intracellular cytokine staining. As shown in Figures 6(a) and 6(b), significantly less NK cells in iNKT KO mice were stained positively for IFN- $\gamma$ at day 5 after Cpn infection, compared with those in WT mice. The percentage of IFN- $\gamma$-producing NK cells in iNKT KO mice was less than half of WT mice. IFN- $\gamma$ production by NK cells partially depended on iNKT cells. Furthermore, we tested the levels of intracellular IFN- $\gamma$ expression in each of the subsets to determine the functional changes in individual NK subsets. We found reduced IFN- $\gamma$ production by all the three major NK subsets (Figure 6(c)), suggesting that the modulating effect of iNKT cells on IFN- $\gamma$ production by NK cells was not restricted to particular NK subsets. Together, the data suggest that iNKT cells can promote the activation and IFN- $\gamma$ production of NK cells following Cpn infection. 


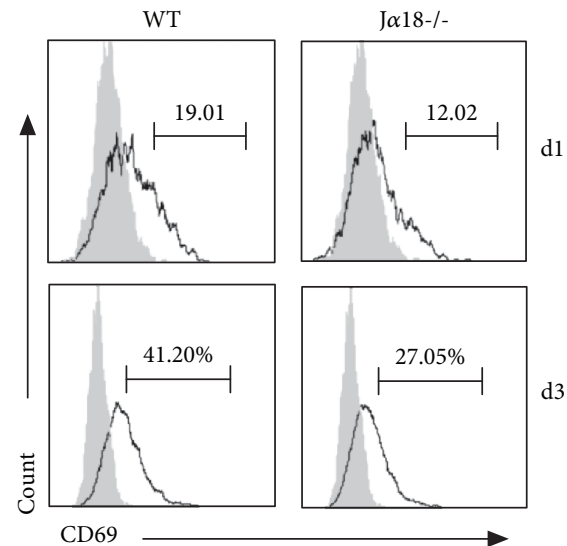

(a)

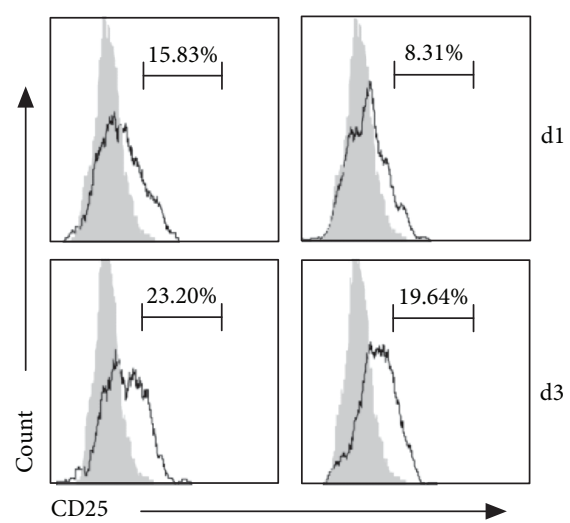

(c)

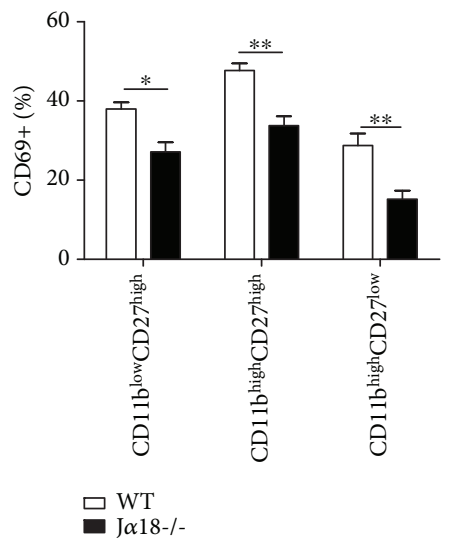

(e)
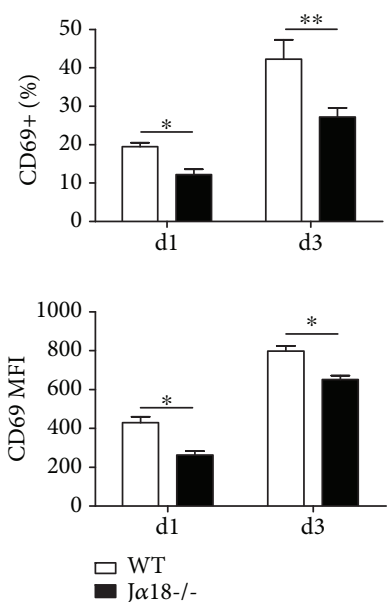

(b)
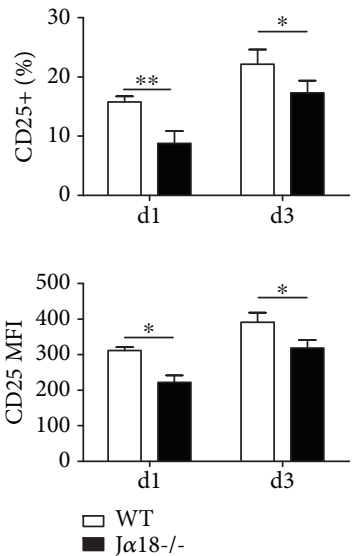

(d)

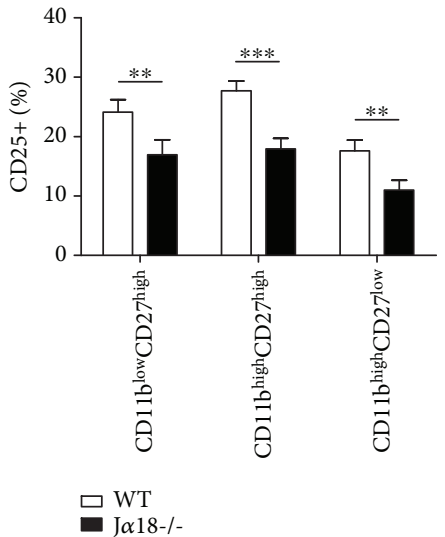

(f)

Figure 5: NK cells from J $\alpha 18-/-$ mice show lower CD69 and CD25 expression in response to Cpn infection. WT and J $\alpha 18-/-$ mice were intranasally infected with Cpn $\left(5 \times 10^{6}\right.$ IFUs) and examined at days 1 and 3 p.i. Splenocytes were prepared for flow cytometry analysis. (a) CD69 expression on NK (NK1.1+CD3e-) cells was analyzed at days 1 and 3 p.i. Representative histograms are shown. Filled gray: isotype control Ab staining; black lines: anti-CD69 Ab staining. (b) Summary of the proportion (upper) and the MFI (lower) of CD69 on NK cells. (c) Representative histograms of CD25 expression on NK cells are shown. Filled gray: isotype control Ab staining; black lines: antiCD25 Ab staining. (d) Summary of the proportion (upper) and the MFI (lower) of CD25 on NK cells. (e) The frequency of CD69 was analyzed on the specified NK cell subsets based on CD11b and CD27 staining at day 3 p.i. (f) The frequency of CD25 was analyzed on the indicated NK cell subsets based on CD11b and CD27 staining at day 3 p.i. The results are shown as mean \pm SD of three mice in each group and are representative of three independent experiments. ${ }^{*} p<0.05$ and ${ }^{* *} p<0.01$. 


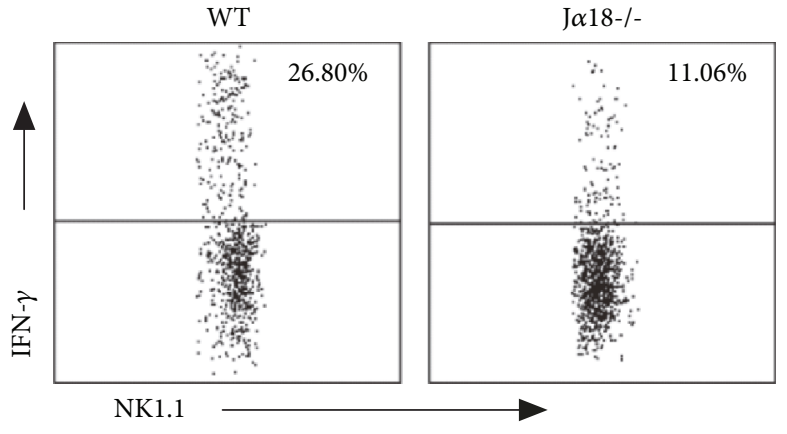

(a)

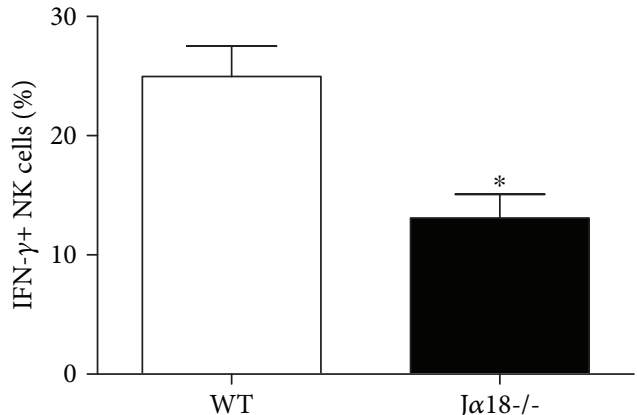

(b)

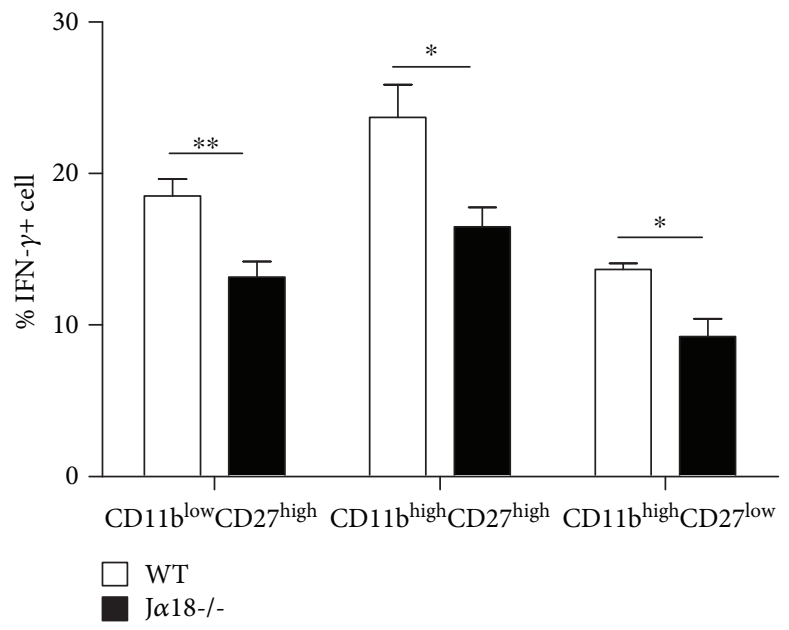

(c)

FIGURE 6: Reduced IFN- $\gamma$ production by NK cells in J $\alpha 18-/-$ mice following Cpn lung infection. Mice were intranasally infected with Cpn $\left(5 \times 10^{6}\right.$ IFU). At day 5 p.i., splenocytes from WT and J $\alpha 18-/-$ mice were stained for NK1.1, CD3e, CD11b, CD27, and IFN- $\gamma$ and analyzed by flow cytometry. (a) Representative dot plots of IFN- $\gamma$ production by NK cells in WT and J $\alpha 18-/-$ mice. (b) The percentage of IFN- $\gamma$-producing NK cells was summarized. (c) The frequency of IFN- $\gamma$ production was analyzed on the specified NK cell subsets based on $\mathrm{CD} 11 \mathrm{~b}$ and $\mathrm{CD} 27$ staining. The data are shown as mean $\pm \mathrm{SD}(n=4)$. One representative experiment of three independent experiments is shown. ${ }^{*} p<0.05$.

3.6. DCs from iNKT-Deficient Mice Show Reduced Ability to Induce NK Cell Activation and IFN- $\gamma$ Production. DC can prime resting NK cell both in mice $[4,32,33]$ and in humans [34]. Previous studies have demonstrated a pivotal role for DC-derived IL-12 in the induction of IFN- $\gamma$-producing NK cells [35]. The level of DC maturation affected the degree of NK activation $[33,36]$. Therefore, it is likely that the reduced NK cell activation and IFN- $\gamma$ production in iNKT-deficient mice are a result of the altered DC function. To directly test this, DCs were isolated from Cpn-infected WT and iNKT $\mathrm{KO}$ mice and cocultured with NK cells from uninfected WT mice for 24 hours. The expression of CD69 and CD25 and production of IFN- $\gamma$ by NK cells were tested by flow cytometry. As shown in Figure 7, both WT-DC and KODC induced enhanced CD69 and CD25 surface expression by NK cells. However, KO-DC-induced CD69 (Figures 7(a) and 7(b)) and CD25 (Figures 7(c) and 7(d)) expression of NK cells was significantly lower than that induced by WTDC. More importantly, NK cells cocultured with KO-DC produced significantly lower levels of IFN- $\gamma$ than those cocultured with WT-DC (Figures 7(e) and 7(f)). Meanwhile,
IFN- $\gamma$ levels in culture supernatants were also significantly lower in KO-DC-NK coculture than in WT-DC-NK coculture (Figure $7(\mathrm{~g})$ ). As a control, neither DC nor NK alone produced detectable IFN- $\gamma$. To further test the role of DCs in iNKT-mediated NK response in vivo, we performed adoptive transfer experiments with DC isolated from $C p n$-infected iNKT KO and WT mice. The activation marker expression and IFN- $\gamma$ production by NK cells were examined at day 3 after Cpn challenge. As shown in Figure 8, significantly lower CD69 and CD25 expression and IFN- $\gamma$ production by NK cells were observed in the recipients of KO-DCs than WTDC recipients. The data suggest that DCs play a critical role in iNKT-mediated NK activation and IFN- $\gamma$ production during $C p n$ infection.

\section{Discussion}

Our data showed a significant modulating effect of iNKT cell on NK cell activation and IFN- $\gamma$ production in lung Cpn infection. Moreover, we found that DCs play an important role in the iNKT-mediated modulation of NK cell function. 


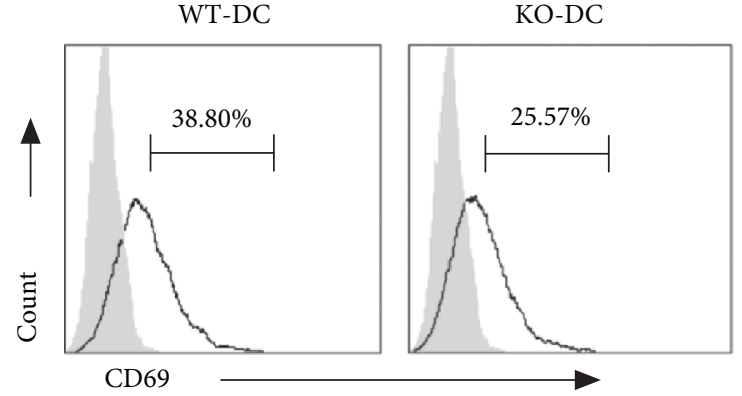

(a)

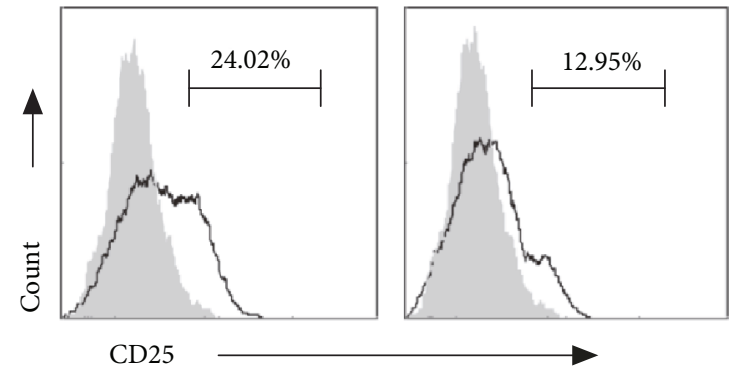

(c)

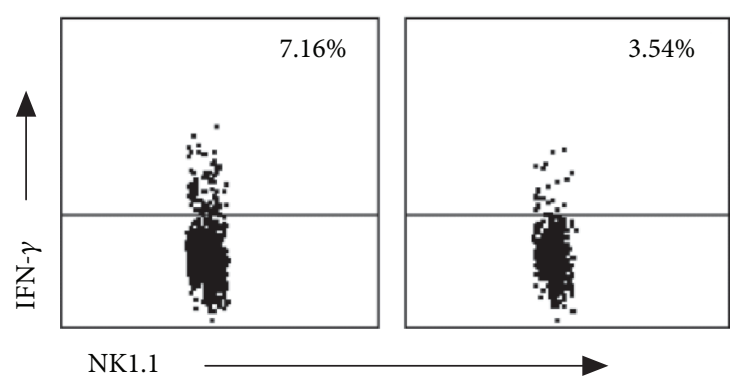

(e)

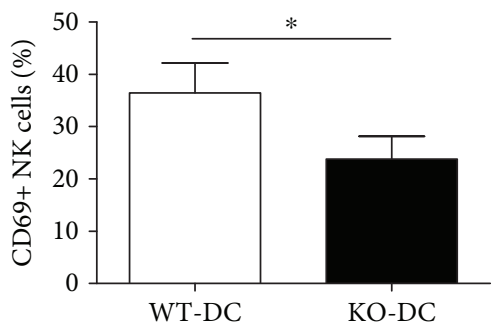

(b)

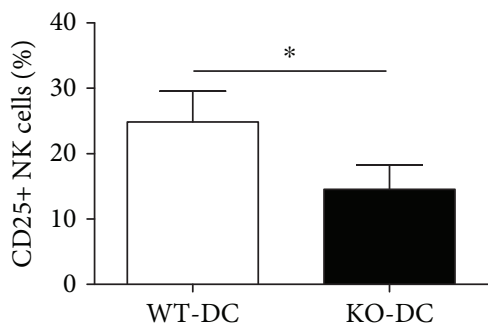

(d)

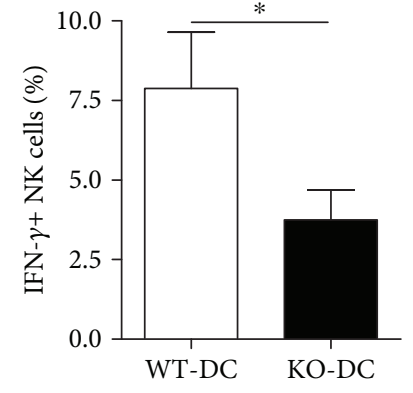

(f)

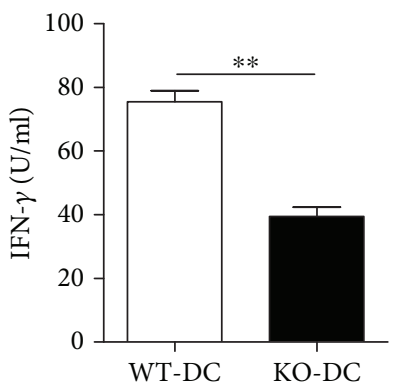

(g)

FIGURE 7: Reduced ability of DCs from Cpn-infected iNKT KO mice to induce activation and IFN- $\gamma$ production by naïve NK cells. DCs were isolated from spleens of iNKT KO mice (KO-DC) and WT mice (WT-DC) at day 5 p.i. NK cells were enriched from the spleen of naïve mice. NK cells $\left(2 \times 10^{5}\right)$ were cocultured with DC $\left(1 \times 10^{6}\right)$ cells in a 96-well round bottom plate. After $48 \mathrm{~h}$, the cells and supernatant were collected for CD69, CD25, and IFN- $\gamma$ staining of the cells and ELISA measurement of IFN- $\gamma$ in the supernatants, respectively. The representative histograms and dot plots for CD69 (a) and CD25 (b) expression and IFN- $\gamma$ production (e) by NK cells are depicted. The percentage of CD69+ (b), CD25+ (d), and IFN- $\gamma+$ (f) NK cells was summarized. (g) The concentration of IFN- $\gamma$ in supernatant was examined by ELISA. The data represent one of three similar experiments and are shown as mean $\pm \mathrm{SD}$. ${ }^{*} p<0.05,{ }^{* *} p<0.01$.

Specifically, we showed that respiratory Cpn infection induced NK cell activation and IFN- $\gamma$ production with dynamic changes of NK subsets. Further comparison of NK cell response in iNKT KO and WT mice revealed a promoting role of iNKT cells in NK cell function, which was demonstrated by decreased expression of activation markers, reduced production of IFN- $\gamma$, and changes of NK subsets in iNKT KO mice. The activation and IFN- $\gamma$ production by NK cells are largely influenced by iNKT cells in Cpn infection although it is not completely dependent on iNKT cells, suggesting a promoting role of iNKT cell on NK cell function. More interestingly, we found in a DC-NK coculture system that DCs isolated from Cpn-infected iNKT KO mice induced lower activation marker expression and less IFN- $\gamma$ production by NK cells than those isolated from WT mice, suggesting a critical role of DCs in iNKT-mediated modulation of
NK function. We also showed in the present study that NK cells play an important protective role in host defense against $C p n$ infection. In line with this, we also found that adoptive transfer of DCs from iNKT KO mice generated less IFN- $\gamma$ production by NK cells than the DCs from WT mice in vivo. Our previous studies focus on the effect of iNKT on DC function in modulating T cells [1] while the current data showed an effect of iNKT on DCs which subsequently modulate NK cell function. We have reported previously that iNKT can significantly influence DC phenotype, cytokine production, subsets, and function in the spleen and lung in chlamydial infections $[1,27,28,31]$. The combined data from previous reports and the current study provide a mechanistic explanation for the previously reported modulating effect of iNKT on NK function [24] by showing the critical role of DCs in this modulating process. Considering our 


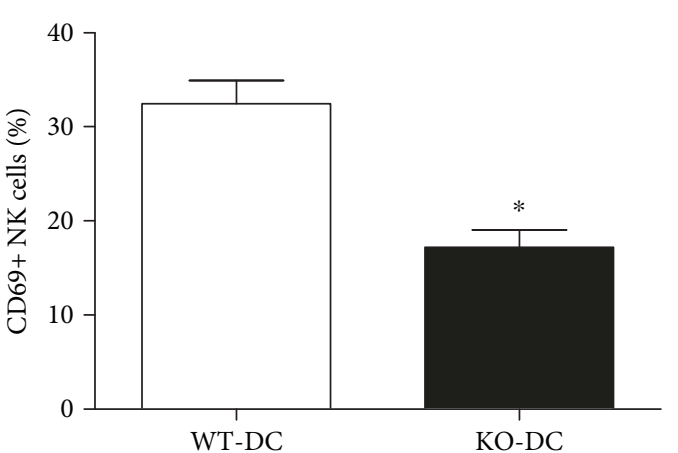

(a)

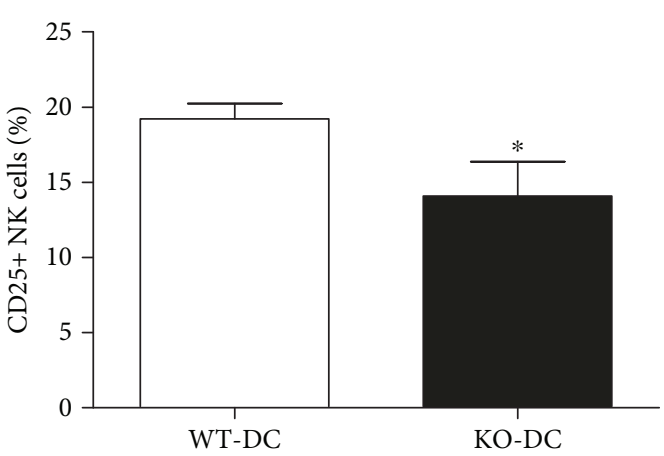

(b)

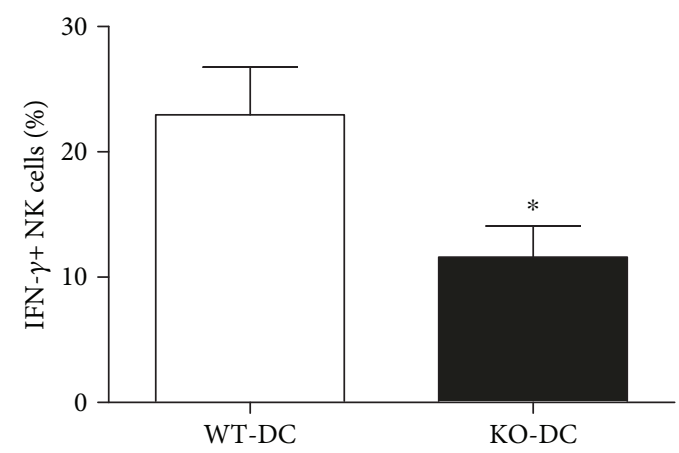

(c)

FIgURE 8: Adoptive transfer of KO-DC induces less activation and IFN- $\gamma$ production by NK cells. Naive recipient mice (C57BL/6) were delivered DCs isolated from spleens of Cpn-infected iNKT KO mice (KO-DC) and WT mice (WT-DC). The recipient mice were sacrificed at day 3 after Cpn challenge. The spleen cells were collected to measure CD69 and CD25 expression and IFN- $\gamma$ production by NK cells using flow cytometry. The percentage of CD69+ (a), CD25+ (b), and IFN- $\gamma+$ (c) NK cells was summarized. The data represent one of three similar experiments and are shown as mean $\pm \mathrm{SD} .{ }^{*} p<0.05$.

previous report on the modulating effect of NK on DCs [27], the findings also suggest a reciprocal influence of DC and NK cells in chlamydial infection.

The study provides new data on the dynamic changes of NK cell responses in lung Cpn infection, showing that NK cells rapidly expanded with upregulated CD69 and CD25 expression and enhanced IFN- $\gamma$ production. More interestingly, the data provided in vivo evidence of NK subset switch in response to Cpn infection. Distinct function of NK subsets based on CD27 and CD11b expression has been reported $[12,37,38]$. We observed that Cpn infection increased the percentage of $\mathrm{CD} 11 \mathrm{~b}{ }^{\text {low }} \mathrm{CD} 27^{\text {high }}$ and $\mathrm{CD} 11 \mathrm{~b}^{\text {high }} \mathrm{CD} 27^{\text {high }}$ NK subsets so consequently reducing the proportion of $\mathrm{CD} 11 \mathrm{~b}^{\text {high }} \mathrm{CD} 27^{\text {low }} \mathrm{NK}$ subset. It has been reported that $\mathrm{CD} 27^{\text {high }} \mathrm{NK}$ cells have a lower threshold for activation and produce more IFN- $\gamma$ compared with $\mathrm{CD} 27^{\text {low }}$ subset [11]. In our infection model, CD $27^{\text {high }} \mathrm{NK}$ cells were the major producer for IFN- $\gamma$ within the whole NK population during Cpn infection (data not shown). The increased proportion of $\mathrm{CD} 27^{\text {high }} \mathrm{NK}$ cells might contribute to high levels of IFN- $\gamma$ production by NK cells after Cpn infection. Although the exact mechanism accounting for $\mathrm{CD} 27^{\text {high }}$ NK cell expansion remains unclear, the following possibilities are likely involved: (1) the proliferation of $\mathrm{CD} 27^{\text {high }}$ NK cells in situ, (2) the migration of immature NK cells from bone marrow, and (3) the cell death or reversion of $\mathrm{CD} 11 \mathrm{~b}^{\text {high }} \mathrm{CD} 27^{\text {low }}$ NK subset.
The effect of iNKT on NK subsets was particularly interesting. It was found that the iNKT KO mice showed higher expansion of $\mathrm{CD} 27^{\text {high }}$ NK subset than WT mice following Cpn infection. Considering the lower threshold of this subset for activation, one might think that the $\mathrm{KO}$ mice had better NK function especially IFN- $\gamma$ production. However, we found that all the NK cell subsets including the CD27 $7^{\text {high }}$ subset in iNKT KO mice showed lower CD69 and CD25 expression and IFN- $\gamma$ production compared with the corresponding subsets in WT mice. The results suggest that the surface markers in defying the functional subsets of NK cells may not be absolute. Although CD27 expression normally suggests higher activation and IFN- $\gamma$ production, the $\mathrm{CD} 27^{\text {high }} \mathrm{NK}$ cells, in the condition of iNKT deficiency, actually expressed lower levels of activation markers and IFN- $\gamma$ than those in WT mice. Therefore, the analysis of cell subsets needs to have a combination of surface markers and cytokine patterns. Moreover, since all the three NK subsets from iNKT KO mice showed lower expression of activation markers and production of IFN- $\gamma$, the modulating effect of iNKT cells on NK cells is not restricted to a particular NK cell subset.

The results of NK-DC coculture study provide new mechanistic data on the modulating effect of iNKT on NK cells by showing the critical role of DCs in this process. Notably, we and others have shown the modulating effect of iNKT and NK cells on DC function $[1,27,28]$. In particular, we found that iNKT as well as NK cell can modulate 
the function of splenic and pulmonary DCs in promoting CD4 and CD8 $T$ cell responses $[27,28]$. The present finding on the promoting effect of DCs from iNKT intact WT mice on NK cells for the production of IFN- $\gamma$ suggests a loop of positive feedback in amplifying the promoting role of iNKT on type $1 \mathrm{~T}$ cell responses in addition to the direct promoting effect on NK effector function. The finding further supports the importance of interactions among multiple types of innate and adaptive immune cells in the expansion and restriction of the scales of inflammatory reactions for immune homeostasis.

Our data showed that NK depletion in immune intact mice led to increased Cpn burden in the lung (Figure 3), suggesting that NK cells are functionally involved in protection against Cpn lung infection. This observation might be considered inconsistent with the study using T cell- and $B$ cell-deficient mice [29, 30]. Indeed, one report showed that $\mathrm{RAG}-1^{-1-} / \gamma \mathrm{cR} \mathrm{R}^{-/-}$and $\mathrm{RAG}-1^{-/-}$mice showed similar susceptibility to Cpn lung infection, suggesting a negligible role of NK cells in Cpn infection [30]. Another report showed that the Cpn load in the lung of RAG-1 ${ }^{-1-}$ mice was not altered after eliminating NK cells using neutralizing Abs [29]. However, we think that our data are not necessarily contradictory with the previous reports. The observed discrepancy might be due to the different mice that were used in the studies: T/B cell deficient $[29,30]$ versus $\mathrm{T} / \mathrm{B}$ intact mice in the present study. When our current study is considered with previously reported ones [29, 30], it might suggest that NK cell plays its protective role though promoting the function of other immune cells, particularly $\mathrm{T}$ and $\mathrm{B}$ cells, rather than directly controlling Cpn lung infection as an effector. The deficiency of $\mathrm{T}$ and $\mathrm{B}$ cells in RAG-1 ${ }^{-/}$mice likely covered up this promoting function of NK cells on Th1 responses though IFN- $\gamma$ production as shown in our previous study [27].

\section{Conclusions}

In summary, our data revealed a significant modulating effect of iNKT cell on NK cell activation and IFN- $\gamma$ production in respiratory $C p n$ infection. Additionally, the results provided a mechanistic explanation for the iNKT-mediated modulation of NK cell function by showing the important role of DCs. The finding has implications on understanding the complexity of cellular networks in respiratory tract chlamydial infection, which should be considered in designing preventive and therapeutic approaches.

\section{Data Availability}

The data used to support the findings of this study are available from the corresponding author upon request.

\section{Conflicts of Interest}

The authors confirm that there are no conflicts of interest.

\section{Acknowledgments}

We are grateful to Dr. Masaru Taniguchi (RIKEN Research Center for Allergy and Immunology) for his generous gift of the $\mathrm{J} \alpha 18$ gene knockout (J $\alpha 18-/-)$ mice. This work was supported by grants jointly funded by Canadian Institutes of Health Research (CIHR) to X.Y. (CCI 92213 and MOP130423) and the National Natural Science Foundation of China (NSFC) to L.Z. (81501761) and W.Z. (30811120425). X.Y. was the Canada Research Chair in Infection and Immunity.

\section{Supplementary Materials}

Figure S1: pulmonary NK cells expand after Cpn lung infection. Figure S2: NK cell depletion in the spleen and lung. Figure S3: the absolute number of NK cells in WT and iNKT $\mathrm{KO}$ mice is similar before and after Cpn infection. (Supplementary Materials)

\section{References}

[1] A. G. Joyee, H. Qiu, Y. Fan, S. Wang, and X. Yang, "Natural killer T cells are critical for dendritic cells to induce immunity in Chlamydial pneumonia," American Journal of Respiratory and Critical Care Medicine, vol. 178, no. 7, pp. 745-756, 2008.

[2] P. Arora, A. Baena, K. O. A. Yu et al., "A single subset of dendritic cells controls the cytokine bias of natural killer $\mathrm{T}$ cell responses to diverse glycolipid antigens," Immunity, vol. 40, no. 1, pp. 105-116, 2014.

[3] M. Lucas, W. Schachterle, K. Oberle, P. Aichele, and A. Diefenbach, "Dendritic cells prime natural killer cells by trans-presenting interleukin 15," Immunity, vol. 26, no. 4, pp. 503-517, 2007.

[4] F. Gerosa, B. Baldani-Guerra, C. Nisii, V. Marchesini, G. Carra, and G. Trinchieri, "Reciprocal activating interaction between natural killer cells and dendritic cells," The Journal of experimental medicine, vol. 195, no. 3, pp. 327-333, 2002.

[5] P. L. Dunn and R. J. North, "Early gamma interferon production by natural killer cells is important in defense against murine listeriosis," Infection and Immunity, vol. 59, no. 9, pp. 2892-2900, 1991.

[6] M. B. Lodoen and L. L. Lanier, "Natural killer cells as an initial defense against pathogens," Current Opinion in Immunology, vol. 18, no. 4, pp. 391-398, 2006.

[7] J. Loh, D. T. Chu, A. K. O'Guin, W. M. Yokoyama, and H. W. Virgin, "Natural killer cells utilize both perforin and gamma interferon to regulate murine cytomegalovirus infection in the spleen and liver," Journal of Virology, vol. 79, no. 1, pp. 661-667, 2005.

[8] A. Silva, D. M. Andrews, A. G. Brooks, M. J. Smyth, and Y. Hayakawa, "Application of CD27 as a marker for distinguishing human NK cell subsets," International Immunology, vol. 20, no. 4, pp. 625-630, 2008.

[9] Y. Hayakawa, N. D. Huntington, S. L. Nutt, and M. J. Smyth, "Functional subsets of mouse natural killer cells," Immunological reviews, vol. 214, no. 1, pp. 47-55, 2006.

[10] L. Chiossone, J. Chaix, N. Fuseri, C. Roth, E. Vivier, and T. Walzer, "Maturation of mouse NK cells is a 4-stage developmental program," Blood, vol. 113, no. 22, pp. 5488-5496, 2009. 
[11] Y. Hayakawa and M. J. Smyth, "CD27 dissects mature NK cells into two subsets with distinct responsiveness and migratory capacity," Journal of immunology, vol. 176, no. 3, pp. 15171524, 2006.

[12] M. Gao, Y. Yang, D. Li et al., "CD27 natural killer cell subsets play different roles during the pre-onset stage of experimental autoimmune encephalomyelitis," Innate Immunity, vol. 22, no. 6, pp. 395-404, 2016.

[13] Z. K. Ballas, C. M. Buchta, T. R. Rosean, J. W. Heusel, and M. R. Shey, "Role of NK cell subsets in organ-specific murine melanoma metastasis," PLoS One, vol. 8, no. 6, p. e65599, 2013.

[14] D. I. Godfrey, H. R. MacDonald, M. Kronenberg, M. J. Smyth, and L. V. Kaer, "NKT cells: what's in a name?," Nature Reviews Immunology, vol. 4, no. 3, pp. 231-237, 2004.

[15] A. Bendelac, O. Lantz, M. E. Quimby, J. W. Yewdell, J. R. Bennink, and R. R. Brutkiewicz, "CD1 recognition by mouse NK1+ T lymphocytes," Science, vol. 268, no. 5212, pp. 863865, 1995.

[16] E. Tonti, G. Galli, C. Malzone, S. Abrignani, G. Casorati, and P. Dellabona, "NKT-cell help to B lymphocytes can occur independently of cognate interaction," Blood, vol. 113, no. 2, pp. 370-376, 2009.

[17] Y. Hayakawa, K. Takeda, H. Yagita et al., "Critical contribution of IFN- $\gamma$ and NK cells, but not perforin-mediated cytotoxicity, to anti-metastatic effect of $\alpha$-galactosylceramide," European Journal of Immunology, vol. 31, no. 6, pp. 1720-1727, 2001.

[18] G. Eberl and H. R. MacDonald, "Selective induction of NK cell proliferation and cytotoxicity by activated NKT cells," European Journal of Immunology, vol. 30, no. 4, pp. 985992, 2000.

[19] C. Carnaud, D. Lee, O. Donnars et al., "Cutting edge: cross-talk between cells of the innate immune system: NKT cells rapidly activate NK cells," Journal of immunology, vol. 163, no. 9, pp. 4647-4650, 1999.

[20] L. S. Metelitsa, O. V. Naidenko, A. Kant et al., "Human NKT cells mediate antitumor cytotoxicity directly by recognizing target cell CD1d with bound ligand or indirectly by producing IL-2 to activate NK cells," The Journal of Immunology, vol. 167, no. 6, pp. 3114-3122, 2001.

[21] P. Riese, S. Trittel, T. May, L. Cicin-Sain, B. J. Chambers, and C. A. Guzman, "Activated NKT cells imprint NK-cell differentiation, functionality and education," European Journal of Immunology, vol. 45, no. 6, pp. 1794-1807, 2015.

[22] M. S. Duthie and S. J. Kahn, "NK cell activation and protection occur independently of natural killer T cells during Trypanosoma cruzi infection," International Immunology, vol. 17, no. 5, pp. 607-613, 2005.

[23] C. Paget, S. Ivanov, J. Fontaine et al., "Potential role of invariant NKT cells in the control of pulmonary inflammation and $\mathrm{CD} 8+\mathrm{T}$ cell response during acute influenza A virus $\mathrm{H} 3 \mathrm{~N} 2$ pneumonia," Journal of Immunology, vol. 186, no. 10, pp. 5590-5602, 2011.

[24] L. Zhao, X. Gao, Y. Peng et al., "Differential modulating effect of natural killer (NK) T cells on interferon- $\gamma$ production and cytotoxic function of NK cells and its relationship with NK subsets in Chlamydia muridarum infection," Immunology, vol. 134, no. 2, pp. 172-184, 2011.

[25] A. G. Joyee, H. Qiu, S. Wang, Y. Fan, L. Bilenki, and X. Yang, "Distinct NKT cell subsets are induced by different Chlamydia species leading to differential adaptive immunity and host resistance to the infections," The Journal of Immunology, vol. 178, no. 2, pp. 1048-1058, 2007.

[26] C. T. Tseng and R. G. Rank, "Role of NK cells in early host response to chlamydial genital infection," Infection and Immunity, vol. 66, no. 12, pp. 5867-5875, 1998.

[27] L. Jiao, X. Gao, A. G. Joyee et al., "NK cells promote type $1 \mathrm{~T}$ cell immunity through modulating the function of dendritic cells during intracellular bacterial infection," The Journal of Immunology, vol. 187, no. 1, pp. 401-411, 2011.

[28] S. Shekhar, Y. Peng, X. Gao et al., "NK cells modulate the lung dendritic cell-mediated Th1/Th17 immunity during intracellular bacterial infection," European Journal of Immunology, vol. 45, no. 10, pp. 2810-2820, 2015.

[29] M. E. Rottenberg, A. Gigliotti Rothfuchs, D. Gigliotti et al., "Regulation and role of IFN-gamma in the innate resistance to infection with Chlamydia pneumoniae," Journal of Immunology, vol. 164, no. 9, pp. 4812-4818, 2000.

[30] A. G. Rothfuchs, M. R. Kreuger, H. Wigzell, and M. E. Rottenberg, "Macrophages, CD4+ or CD8+ cells are each sufficient for protection against Chlamydia pneumoniae infection through their ability to secrete IFN-gamma," Journal of Immunology, vol. 172, no. 4, pp. 2407-2415, 2004.

[31] A. G. Joyee, J. Uzonna, and X. Yang, "Invariant NKT cells preferentially modulate the function of $\mathrm{CD} 8 \alpha+$ dendritic cell subset in inducing type 1 immunity against infection," The Journal of Immunology, vol. 184, no. 4, pp. 2095-2106, 2010.

[32] N. C. Fernandez, A. Lozier, C. Flament et al., "Dendritic cells directly trigger NK cell functions: cross-talk relevant in innate anti-tumor immune responses in vivo," Nature Medicine, vol. 5, no. 4, pp. 405-411, 1999.

[33] J. Xu, A. K. Chakrabarti, J. L. Tan, L. Ge, A. Gambotto, and N. L. Vujanovic, "Essential role of the TNF-TNFR2 cognate interaction in mouse dendritic cell-natural killer cell crosstalk," Blood, vol. 109, no. 8, pp. 3333-3341, 2007.

[34] G. Ferlazzo, M. L. Tsang, L. Moretta, G. Melioli, R. M. Steinman, and C. Munz, "Human dendritic cells activate resting natural killer (NK) cells and are recognized via the NKp30 receptor by activated NK cells," The Journal of Experimental Medicine, vol. 195, no. 3, pp. 343-351, 2002.

[35] C. Borg, A. Jalil, D. Laderach et al., "NK cell activation by dendritic cells (DCs) requires the formation of a synapse leading to IL-12 polarization in DCs," Blood, vol. 104, no. 10, pp. 3267-3275, 2004.

[36] L. Vujanovic, D. E. Szymkowski, S. Alber, S. C. Watkins, N. L. Vujanovic, and L. H. Butterfield, "Virally infected and matured human dendritic cells activate natural killer cells via cooperative activity of plasma membrane-bound TNF and IL-15," Blood, vol. 116, no. 4, pp. 575-583, 2010.

[37] S. Paul, N. Kulkarni, Shilpi, and G. Lal, "Intratumoral natural killer cells show reduced effector and cytolytic properties and control the differentiation of effector Th1 cells," Oncoimmunology, vol. 5, no. 12, article e1235106, 2016.

[38] K. Meinhardt, I. Kroeger, R. Bauer et al., "Identification and characterization of the specific murine NK cell subset supporting graft-versus-leukemia- and reducing graft-versus-hosteffects," Oncoimmunology, vol. 4, no. 1, article e981483, 2015. 


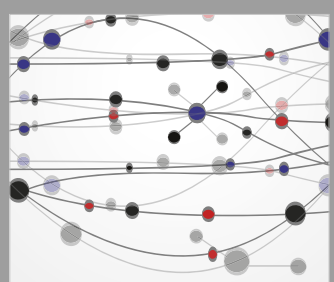

The Scientific World Journal
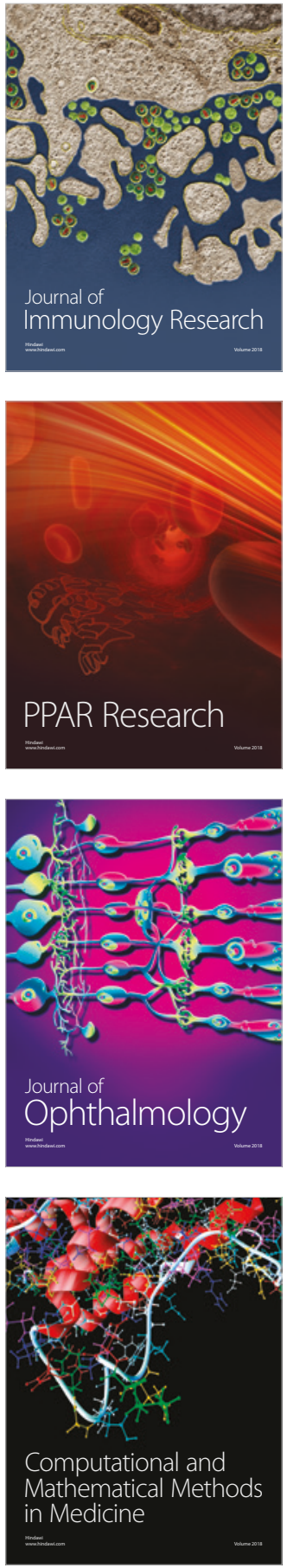

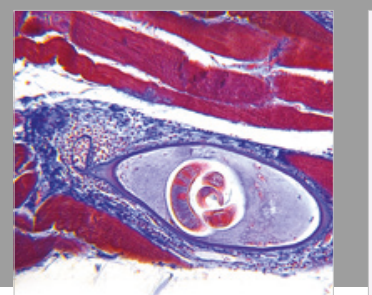

Gastroenterology Research and Practice

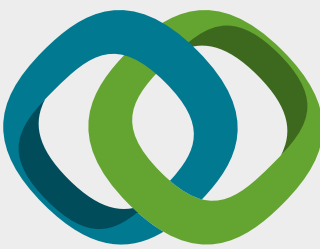

\section{Hindawi}

Submit your manuscripts at

www.hindawi.com
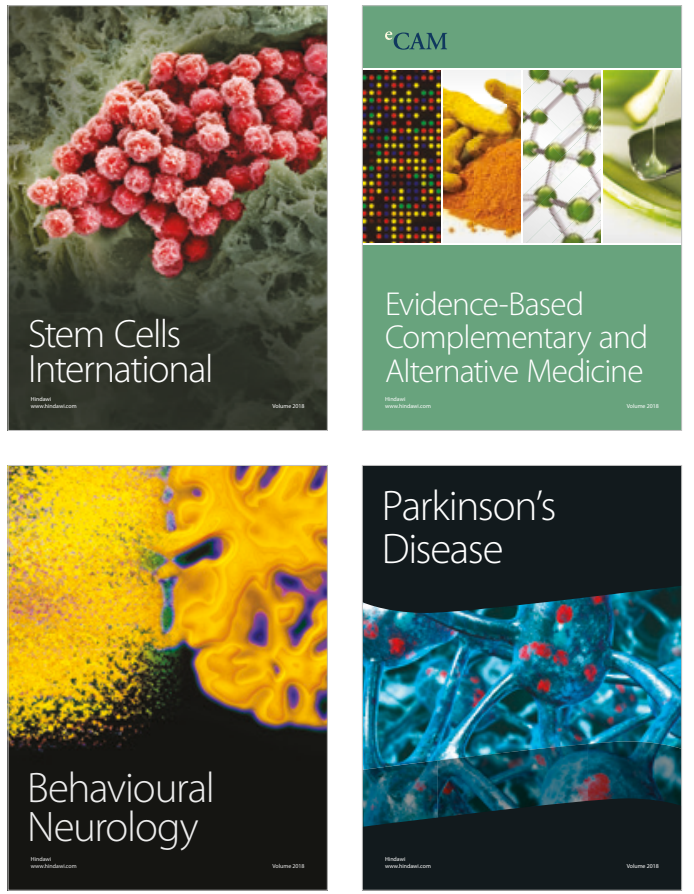

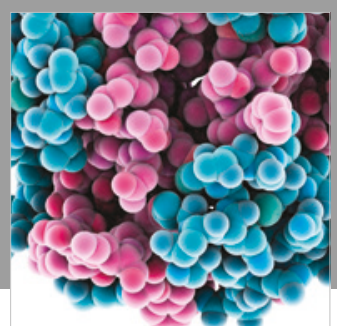

ournal of

Diabetes Research

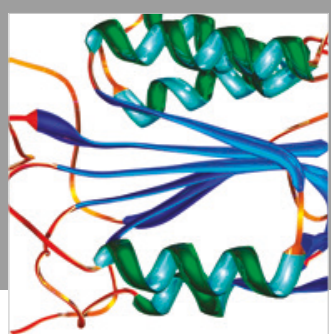

Disease Markers
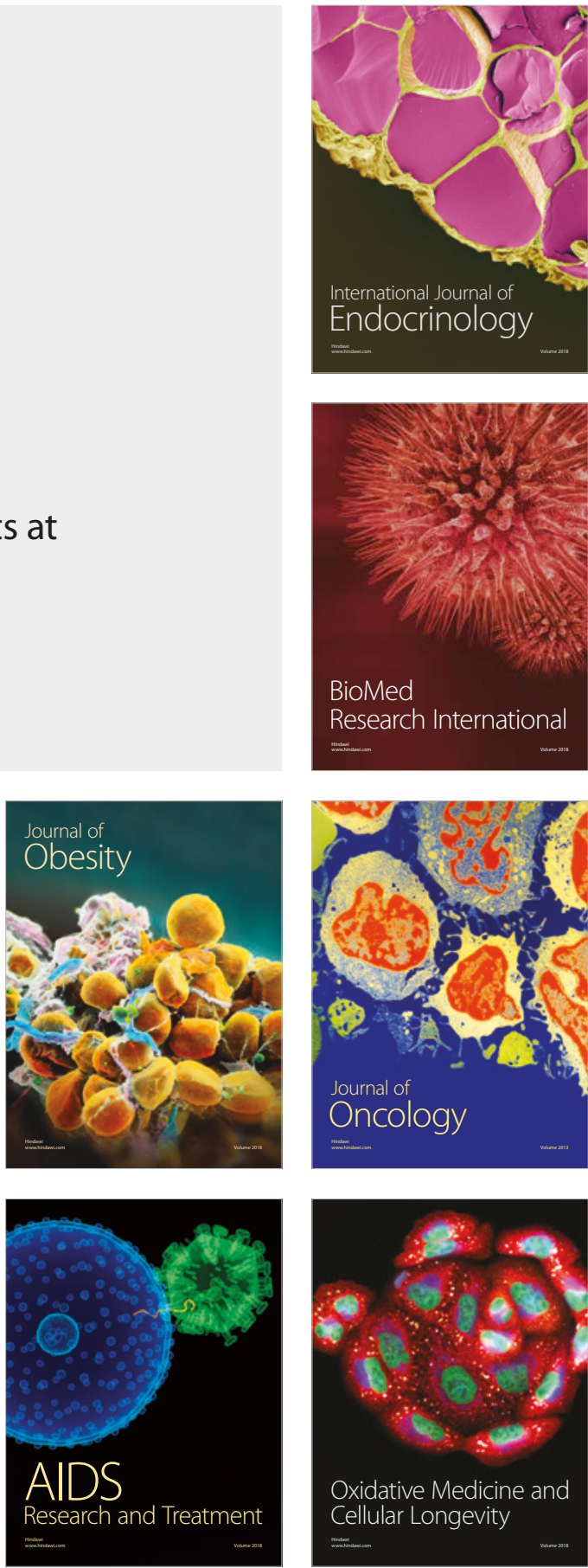